imum of $\frac{7}{8}$ inch in diameter $\times 6$ inches long.

The modified temperature control circuit of LaPlante (1966) (Fig. 2), supplies power to the heater through an SCR which is turned on whenever the charge across $C_{1}$ at point $(A)$ is sufficiently positive. The net charge across $C_{1}$ is determined by the cancellation effect of the positive charging branch containing the temperature adjust $R_{1}$ and the negative charging branch containing the thermistor $R_{\mathrm{t}}$.

When operating above $25^{\circ} \mathrm{C}, S_{1}$ is placed on HEAT which renders the refrigeration unit inoperative and shorts $R_{4}$ and $R_{5}$ in the thermistor branch. Below $25^{\circ} \mathrm{C}, S_{1}$ is switched to $\mathrm{COOL}$ turn-

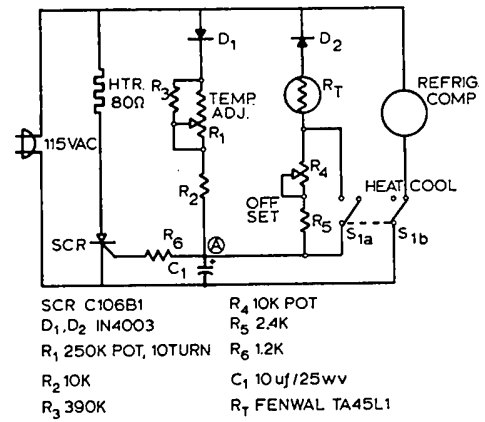

Fig. 2. Temperature control circuit. ing on the refrigeration unit which runs continuously. This also introduces $R_{4}$ and $R_{5}$ into the thermistor branch which enhances the positive charge effect at point $(A)$ by the temperature adjust $R_{1}$. The result is a greater heater conduction angle essential in heating the air cooled by the freezer tray $(D) . R_{4}$ is adjusted for zero temperature change when switching from $H E A T$ to $C O O L$ at $25^{\circ} \mathrm{C}$.

An average rate of temperature decrease of $1^{\circ} \mathrm{C} /$ day $^{*}$ is achieved by using a 1 RPD motor ( $Q$ ). It is coupled through $5: 1$ reduction to the spur gear $(R)$ which is attached to the temperature adjust control $R_{1}$ (10 turn pot.). Other rates may be obtained by using motors of different speeds.

After $R_{4}$ has been correctly adjusted, the chamber may be operated in either HEAT or $C O O L$ for temperatures between $25-30^{\circ} \mathrm{C}$.

Five chambers have now been in rather heavy use for two years; no problems have arisen in regard to the cooling ability of the refrigeration units.

* This is the average rate measured across the full range i.e. $0-45^{\circ} \mathrm{C}$. The temperature $v s$. dial response is nonlinear and is shown in Fig. 3. The actual rate of temperature change would be closer to $1.75^{\circ} \mathrm{C} /$ day above $10^{\circ} \mathrm{C}$ and approximately $0.5^{\circ} \mathrm{C} /$ day from 10 to $0^{\circ} \mathrm{C}$.

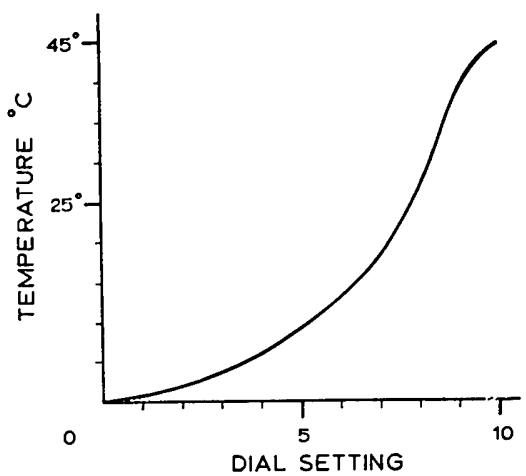

Fig. 3. Temperature vs. dial setting.

Detailed drawings are available from the author.

\section{Reference}

LAPLANTE, D. E. (1966). Electronics, 38 (28), 83.

MARIo Buscemi JR

Medical Foundation of Buffalo

73 High Street

Buffalo

New York 14203

U.S.A.

(Received 10 April 1972;

accepted 8 June 1972)

\title{
Notes and News
}

Announcements and other items of crystallographic interest will be published under this heading at the discretion of the Editorial Board. The notes (in duplicate) should be sent to the Exesutive Secretary of the International Union of Crystallography (J. N. King, International Union of Crystallography, 13 White Friars, Chester CH1 1NZ, England).

\section{Early Papers on Diffraction of $\mathrm{X}$-rays by Crystals. Volume II}

Volume II of this collection appeared in 1972. It contains more than 90 papers, covering the development of X-ray crystallography in the 'trial and error' period, the (re-)birth of the Fourier method, and the discovery of the Patterson synthesis. The book is concluded with Patterson's discovery (1934) of the $F^{2}$ series, as described in his second, more detailed and extended paper of 1935. The papers are arranged in such a way as both to form a history of the science and to serve as a teaching aid.

Early Papers, Vol. II is obtainable directly from the publishers, A. Oosthoek's Uitgevers Mij. N.V., Domstraat 5-13, Utrecht, The Netherlands, from Polycrystal Book Service, P.O. Box 11567, Pittsburgh, Pa. 15238, U.S.A., or from any bookseller, at a price of 90 Netherlands guilders. 